\title{
Prevalence of Anxiety and Depressive disorders and the Role of Coping Strategies in females with Infertility
}

\author{
Ami Pawar' ${ }^{1}$, Bindoo S. Jadhav', Bharat R. Shah ${ }^{3}$ \\ ${ }^{1}$ Assistant Professor, Department of Psychiatry, H.B.T. Medical College and R.N. Cooper Municipal \\ General Hospital, Mumbai. \\ ${ }^{2}$ Professor, Department of Psychiatry, K.J. Somaiya Medical College, Hospital and Research Centre. \\ ${ }^{3}$ Professor and Head, Department of Psychiatry, K.J. Somaiya Medical College, Hospital and Research \\ Centre. \\ Corresponding author: Bindoo Jadhav \\ Email-blmaru@gmail.com
}

\begin{abstract}
Background: Adjustment, anxiety and depressive disorders are amongst the most common psychiatric morbidities in infertile women in previous studies. Different women cope with the unpredictable, chronic stress of infertility in different ways. Coping strategies may have an impact on the development of psychiatric morbidity. Hence this study was undertaken.

Methods: A cross sectional study was conducted by interviewing 68 consecutive patients with primary or secondary infertility. Socio-demographic details were taken using the study proforma. Psychiatric morbidity was diagnosed as per ICD-10 criteria. Severity was assessed using HAM-A and MADRS. Coping was evaluated on the COMPI Coping Strategy Scale. Statistical Packages of Social Sciences version 20 was used to compile, tabulate and analyze the data.

Results: A majority $(67.7 \%)$ of infertile females had psychiatric morbidity, the most common being Adjustment disorder (37\%), followed by Mixed anxiety and depressive disorder (32.6\%) and Mood (depressive) disorder (30.4\%).

Conclusion: A high use of active confronting and meaning based coping was seen in majority of the females who did not have psychiatric morbidity. The use of active confronting coping in majority (64.7 \%) of those with Adjustment disorder was found to be statistically significant.
\end{abstract}

Keywords: Psychiatric morbidity, infertility, coping, prevalence.

(Paper received $-13^{\text {th }}$ December 2018, Peer review completed $-3^{\text {rd }}$ March 2019)

(Accepted $-6^{\text {th }}$ March 2019)

\section{INTRODUCTION}

The World Health Organisation (WHO) defines infertility as the "lack of conception after at least 12 months of unprotected intercourse [1]. It is perceived as a problem across virtually all cultures and societies, prevalent in approximately 10 to $20 \%$ of couples [2-3]. Though in some cases, the childless life style enhances life satisfaction, yet it is diminishing for others, for whom parenthood is a personal goal. Continuing advances in the field of obstetrics and gynaecology and the intrusive nature of infertility management are challenging experiences for the patients and physicians [4]. Hence it follows that childlessness often creates enormous problems for infertile couples, especially for the women who are generally blamed for the infertility status of couples [5-6]. Previous studies that have assessed the prevalence of psychiatric morbidity (pre-existing or newly emergent) in couples attending a fertile clinic, have found anxiety and depressive disorders to be amongst the most common diagnoses in them, more so in the women [7-8]. A link has also been suggested between anxiety-depression dynamics involving the hypothalamic-pituitary-adrenal axis (e.g. anxietyinduced hyperprolactinaemia) [9-10] and failure to conceive. 
Coping in its most traditional definition, is a way of controlling and regulating stress [11]. Infertility can be conceptualized as a chronic, unpredictable and uncontrollable stressor that may exceed an individual's coping resources [12]. Coping with infertility may call for varying coping strategies. Schmidt et al in 2005 [13] categorised coping strategies used into 4 broad headings based on their conceptual content: (i) activeavoidance strategies (ii) active-confronting strategies (iii) passive-avoidance strategies and (iv) meaningbased coping. Appropriate psychological interventions aimed at decreasing psychiatric morbidity would help patients face infertility related stress and challenges in a better manner by use of healthier coping strategies. Very few studies have studied the coping strategies used by females with infertility in the Indian scenario using a coping questionnaire specifically aimed at measuring coping strategies in relation to infertility. Hardly any Indian studies have commented on the relationship between anxiety, depression and the coping strategy used. With this background in mind, the above study was undertaken. The study had the following aims -

1. To assess the prevalence of anxiety disorders and depressive disorders in females with infertility.

2. To study the coping strategies used by females with infertility.

3. To study the relationship of anxiety and depressive disorders with the coping strategy used.

\section{METHODOLOGY}

Study area: The study was conducted in the outpatient department of obstetrics and gynaecology in a tertiary care teaching hospital in Mumbai.

Study population: The study population consisted of women who were literate and diagnosed with primary or secondary infertility by the gynaecologist.

Sampling method: Simple random sampling.

Study Design: Single Interview Cross sectional study

Sample Size: The sample size was calculated based on the statistical formula for quantitative data, i.e. $\mathrm{n}=$ $4 \mathrm{pq} / \mathrm{L}^{2}$

$\mathrm{p}=$ proportion $=62 \%$ (previous reference) $[14]$

$\mathrm{q}=100-\mathrm{p}=38$

$\mathrm{L}=$ Allowable Error $=20 \%$ of $\mathrm{p}=12.4$

Using the above formula, at $95 \%$ confidence level, and $80 \%$ power of study, the estimated sample size at $20 \%$ allowable error was 62 . Non response rate of $10 \%$ was considered. The corrected sample size was $n=$ 68.

Time Frame: One year (2015-2016)

Tools for Assessment:

1. Study Proforma: It consisted of questions regarding socio-demographic variables like age, education level, occupation level, duration of marriage, type of family and socioeconomic status.

2. Kuppuswamy socio-economic status scale [15]: The scale takes into account education, occupation and income of the family to categorise families into upper, upper middle, lower middle, lower upper and lower socio-economic status.

3. ICD-10: Classification of Mental and Behavioural Disorders [16]: WHO Guidelines were used to diagnose the presence of anxiety disorders and depressive disorders.

4. MADRS [17]: The Montgomery-Asberg Depression Scale (MADRS) is a ten-item diagnostic questionnaire used frequently to measure the severity of depressive episodes. A score between 0 to 6 indicates absence of depressive symptoms, 7 to 19 indicates mild depression; 20 to 34 moderate depression and $>34$ indicates severe depression.

5. HAM-A [18]: The Hamilton Anxiety Rating Scale (HAM-A) is a clinician rated scale developed to measure the severity of anxiety symptoms. The scale consists of 14 items. Each item is scored on a scale of 0 (not present) to 4 (severe), with a total score range of $0-56$, where 14-17 indicates mild anxiety, 18-24 moderate anxiety, and 25-30 severe anxiety.

6. COMPI Coping Strategies Scale [13]: The Copenhagen Multicentre Psychosocial Infertility Coping Strategy Scale is a 19 item self-administered coping questionnaire specifically aimed at measuring coping strategies in relation to the specific stressor- infertility. The items are categorized 
into four subscales based on their conceptual content: (i) active-avoidance strategies (4 items) (e.g. avoiding being with pregnant women or children); (ii) active-confronting strategies (7 items) (e.g. showing feelings, asking others for advice); (iii) passive-avoidance strategies (3 items)(e.g. hoping for a miracle); and (iv) meaning-based coping ( 5 items)(e.g. thinking about the fertility problem in a positive light, finding other goals in life). Higher scores indicated more use of the specific coping subscale. A Hindi version of the scale was prepared for those who could not read English. This was validated by translating it in Hindi and back-translating it in English by two trained mental health professionals.

\section{Inclusion criteria}

- Females diagnosed with infertility (primary or secondary).

- Females giving informed consent for the study.

\section{Exclusion criteria}

- Females with pre-existing psychiatric morbidity (except addictions).

- Females who are already on psychotropic medications.

- Females who are illiterate or having difficulty reading and comprehending the tool used in either English or Hindi.

\section{STATISTICAL ANALYSIS}

The data thus collected was compiled, tabulated and analysed by using Microsoft Excel 2007 and subjected to analysis using the Statistical Packages of Social Sciences version 20. Frequency, percentage, mean, range, standard deviation and graphs (bar diagram, pie charts) were used, and ROC curve was plotted for data presentation and summarisation. The test of significance used was the Chi-square test.

\section{RESULTS}

A total of 68 females diagnosed with infertility were recruited for the study and assessed. Majority of the females $(45.6 \%)$ were in the age group of $26-30$ years. The mean age of the infertile females was $27.8( \pm 3.78)$ years and range was between 20-40 years. Out of the total number recruited, a majority (32.4\%) had completed middle school (i.e. up to standard 10), and a small number (10.3\%) were post-graduates. Most of the patients $(63.2 \%)$ were housewives. The mean duration of marriage was $5.2( \pm 3.37)$ years with range between 1 year 4 months and 18 years. Most of the females (69.1\%) stayed in a joint family. The socioeconomic status was determined based on the Kuppuswamy classification [15]. A majority (60.3\%) of the study population belonged to the lower middle class, followed by the upper middle class (26.5\%). $5.9 \%$ belonged to the upper class. The recruited females having infertility were screened through clinical interview and using rating scales for presence of anxiety and depressive disorders; of the total number of patients recruited, psychiatric morbidity was seen in a majority i.e. 46 out of $68(67.7 \%)$ females with infertility.

The type of psychiatric morbidity- out of those having psychiatric morbidity, a majority (37\%) had an ICD10 diagnosis of Adjustment disorder. Mixed anxiety and depressive disorder, classified under ICD-10 as "Other anxiety disorders" was seen in $32.6 \%$ of those with psychiatric morbidity. Mood disorders were found in $30.4 \%$ of those with psychiatric morbidity, all of which belonged to the spectrum of depressive disorders listed in ICD-10.

Those having an ICD-10 diagnosis of Adjustment disorder, an equal number i.e. $35.2 \%$ had a diagnosis of Adjustment disorder with mixed anxiety and depressive reaction and Adjustment disorder with brief depressive reaction respectively. The ICD -10 classifies a diagnosis of mixed anxiety and depressive disorder under the category of "Other anxiety disorders". All the females diagnosed thus of having an anxiety disorder also had presence of depressive symptoms and fulfilled the ICD-10 criteria for mixed anxiety and depressive disorder. Out of those having psychiatric morbidity, $32.6 \%$ had a diagnosis of mixed anxiety and depressive disorder. No other type of anxiety disorder was found in the sample of women studied.

In addition to clinical interview, all the respondents were administered the Hamilton Anxiety Rating Scale (HAM-A) to determine presence and severity of anxiety symptoms. Those patients with psychiatric 
morbidity, $37 \%$ were shown to have mild anxiety; and $17.4 \%$ had moderate anxiety on the HAM-A. None of the respondents screened positive for severe anxiety on HAM-A. Thus, a total of $54.4 \%(37 \%+17.4 \%)$ of those having psychiatric morbidity screened positive for anxiety as per HAM-A, and were clinically diagnosed as per ICD-10 criteria as either "Adjustment disorder with mixed anxiety and depressive reaction" or "Mixed anxiety and depressive disorder". Out of those having a mood (depressive) disorder, a majority (42.9\%) had a mild depressive episode. $28.6 \%$ of those with a depressive disorder were diagnosed as dysthymia with moderate depressive episode, $21.4 \%$ had a diagnosis of moderate depressive episode and a minority $(7.1 \%)$ was diagnosed as dysthymia with mild depressive episode. In addition to clinical interview, all the respondents were administered the Montgomery Asberg Depression Scale (MADRS) to determine presence and severity of depressive symptoms. In the sample studied, all patients having psychiatric morbidity ( $\mathrm{n}=46,100 \%)$ screened positive for depression on MADRS. Of those patients with psychiatric morbidity a majority (73.9\%) were shown to have mild depression with a score between 7 and 19; and 26.1 $\%$ had moderate depression scoring between 20-34 points on the MADRS. None of the respondents in the sample showed severe depression on MADRS.

All the four coping strategies were used by females with infertility. An ROC Curve was plotted to decide the cut-offs of coping strategies used by females with infertility for better prediction of psychiatric morbidity with maximum possible sensitivity and specificity [19].

Table 1 shows the cut-off scores of each of the coping strategies used by females with infertility, determined by plotting of ROC curve along with the range, mean and standard deviation. It also depicts that nearly $60 \%$ of the respondents scored above the respective cut offs for each coping strategy indicating a high use of all four coping strategies in the population studied. A majority of the respondents (64.7\%) scored above the cut off for passive avoidance, followed by active avoidance (63.2\%), active confronting (60.3\%) and meaning based coping $(57.4 \%)$.

Table 1: Coping Strategies and Frequency of Infertile Females using Each Strategy (n=68)

\begin{tabular}{|c|c|c|c|c|}
\hline Coping strategy used & Score (p & nts) & $\begin{array}{l}\text { Frequency of } \\
\text { patients* }\end{array}$ & 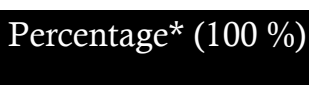 \\
\hline $\begin{array}{l}\text { Active avoidance } \\
\text { Max score }=16\end{array}$ & $\begin{array}{l}\text { Above } \\
\text { cut-off }\end{array}$ & $>6$ & 43 & $63.2 \%$ \\
\hline $\begin{array}{l}\text { Cut off }=6 \\
\text { Sample mean }=7.91(2.670) \\
\text { Range }=4-14\end{array}$ & $\begin{array}{l}\text { Below } \\
\text { cut-off }\end{array}$ & $\leq 6$ & 25 & $36.8 \%$ \\
\hline $\begin{array}{l}\text { Active confronting } \\
\text { Max score=28 }\end{array}$ & $\begin{array}{l}\text { Above } \\
\text { cut-off }\end{array}$ & $>14$ & 41 & $60.3 \%$ \\
\hline $\begin{array}{l}\text { Cut off }=14 \\
\text { Sample mean }=15.22 \\
\text { Range }=10-26\end{array}$ & $\begin{array}{l}\text { Below } \\
\text { cut-off }\end{array}$ & $\leq 14$ & 27 & $39.7 \%$ \\
\hline $\begin{array}{l}\text { Passive avoidance } \\
\text { Max score }=12\end{array}$ & $\begin{array}{l}\text { Above } \\
\text { cut-off }\end{array}$ & $>7$ & 44 & $64.7 \%$ \\
\hline $\begin{array}{l}\text { Cut off }=7 \\
\text { Sample mean }=8.47 \\
\text { Range=3-12 }\end{array}$ & $\begin{array}{l}\text { Below } \\
\text { cut-off }\end{array}$ & $\leq 7$ & 24 & $35.3 \%$ \\
\hline $\begin{array}{l}\text { Meaning based } \\
\text { Max score }=\mathbf{2 0}\end{array}$ & $\begin{array}{l}\text { Above } \\
\text { cut-off }\end{array}$ & $>11$ & 39 & $57.4 \%$ \\
\hline $\begin{array}{l}\text { Cut off }=11 \\
\text { Sample mean }=12.66 \\
\text { Range }=6-20\end{array}$ & $\begin{array}{l}\text { Below } \\
\text { cut-off }\end{array}$ & $\leq 11$ & 29 & $42.6 \%$ \\
\hline
\end{tabular}

*each patient used more than one coping strategy

Table 2 shows a correlation between psychiatric morbidity and coping strategies. Out of those with psychiatric morbidity, a majority (67.4\%) had a score of more than 6 on active avoidance coping, indicating a high use of this coping strategy in this subgroup of respondents. $54.5 \%$ of those without psychopathology had a score above the cut off for this coping strategy. This association was not statistically significant. Half 
(50\%) of the respondents with psychiatric morbidity had a score of more than 14 on use of active confronting coping. A larger percentage (81.8\%) of those with no psychiatric morbidity scored above the cut off score, indicating a high use of this coping strategy amongst this group. This finding was found to be statistically significant with a $\mathrm{p}$ - value of 0.012 .

A majority $(69.6 \%)$ of those with psychiatric morbidity had a score of more than 7 on passive avoidance coping, indicating a high use of this coping strategy in this subgroup of respondents. This association was not statistically significant. From those who did not have psychopathology a majority (81.8\%) had a score of more than 11 on meaning-based coping, indicating a high use of this coping strategy in this subgroup of respondents. This association was found to be statistically significant with a p-value of 0.005 .

Table 2: Correlation of Psychiatric Morbidity with Coping Strategies Used $(n=68)$

\begin{tabular}{|c|c|c|c|c|c|}
\hline \multicolumn{2}{|c|}{ COPING STRATEGY } & \multicolumn{4}{|c|}{ PSYCHIATRIC MORBIDITY } \\
\hline \multirow{3}{*}{$\begin{array}{l}\text { Active } \\
\text { avoidance } \\
\text { coping }\end{array}$} & Score on 16 & $\begin{array}{l}\begin{array}{l}\text { Present } \\
(n=46)\end{array} \\
\end{array}$ & $\begin{array}{l}\text { Percentage } \\
(100 \%)\end{array}$ & $\begin{array}{l}\text { Absent } \\
(\mathrm{n}=22)\end{array}$ & $\begin{array}{l}\text { Percentage } \\
(100 \%)\end{array}$ \\
\hline & $>6$ & 31 & $67.4 \%$ & 12 & $54.5 \%$ \\
\hline & $\leq 6$ & 15 & $32.6 \%$ & 10 & $45.5 \%$ \\
\hline \multicolumn{6}{|c|}{ Chi square value $=1.056 ; p$ - value $=0.304 ;$ not statistically significant } \\
\hline \multirow{3}{*}{$\begin{array}{l}\text { Active } \\
\text { confronting } \\
\text { coping }\end{array}$} & $\begin{array}{ll}\text { Score on } \\
28\end{array}$ & $\begin{array}{l}\begin{array}{l}\text { Present } \\
(n=46)\end{array} \\
(n-1)\end{array}$ & $\begin{array}{l}\text { Percentage } \\
(100 \%)\end{array}$ & $\begin{array}{l}\text { Absent } \\
(\mathrm{n}=22)\end{array}$ & $\begin{array}{l}\text { Percentage } \\
(100 \%)\end{array}$ \\
\hline & $>14$ & 23 & $50 \%$ & 18 & $81.8 \%$ \\
\hline & $\leq 14$ & 23 & $50 \%$ & 04 & $18.2 \%$ \\
\hline \multicolumn{6}{|c|}{ Chi square value $=6.294 ; \mathrm{p}$ - value $=0.012 ;$ Statistically significant } \\
\hline \multirow{3}{*}{$\begin{array}{l}\text { Passive } \\
\text { avoidance } \\
\text { coping }\end{array}$} & Score on 12 & $\begin{array}{l}\begin{array}{l}\text { Present } \\
(n=46)\end{array} \\
(n-10\end{array}$ & $\begin{array}{l}\text { Percentage } \\
(100 \%)\end{array}$ & $\begin{array}{l}\text { Absent } \\
(\mathrm{n}=22)\end{array}$ & $\begin{array}{l}\text { Percentage } \\
(100 \%)\end{array}$ \\
\hline & $>7$ & 32 & $69.6 \%$ & 12 & $54.5 \%$ \\
\hline & $\leq 7$ & 14 & $30.4 \%$ & 10 & $45.5 \%$ \\
\hline \multicolumn{6}{|c|}{ Chi square value $=1.470 ; p$ - value $=0.225 ;$ not statistically significant } \\
\hline \multirow{3}{*}{$\begin{array}{l}\text { Meaning } \\
\text { based coping }\end{array}$} & Score on 20 & $\begin{array}{l}\begin{array}{l}\text { Present } \\
(n=46)\end{array} \\
\end{array}$ & $\begin{array}{l}\text { Percentage } \\
(100 \%)\end{array}$ & $\begin{array}{l}\text { Absent } \\
(\mathrm{n}=22)\end{array}$ & $\begin{array}{l}\text { Percentage } \\
(100 \%)\end{array}$ \\
\hline & $>11$ & 21 & $45.7 \%$ & 18 & $81.8 \%$ \\
\hline & $\leq 11$ & 25 & $54.3 \%$ & 04 & $18.2 \%$ \\
\hline
\end{tabular}

Table 3 shows the correlation across diagnoses of coping strategies used viz.

Active avoidance coping: A majority of respondents having an ICD-10 diagnosis of a mood (depressive) disorder (85.7\%) and mixed anxiety and depressive disorder (73.3\%) scored above the cut off score on active avoidance coping, indicating a high use of this coping strategy in both these subgroups. The association described was not statistically significant.

Active confronting coping: The table shows a majority (64.7\%) of respondents having an ICD-10 diagnosis of an adjustment disorder scored above the cut off score on active confronting coping, indicating a high use of this coping strategy is this subgroup. A larger number (73.3\%) of respondents having mixed anxiety and depressive disorder scored below the cut off for this strategy, indicating lower use of this strategy in the anxiety disorder group. The association was found to be statistically significant ( $p$ - value $=0.009$ ).

Passive avoidance coping: A majority of respondents having an ICD-10 diagnosis of a mixed anxiety and depressive disorder (86.7\%) and mood(depressive) disorder (71.4\%) scored above the cut off score on passive avoidance coping, indicating a high use of this coping strategy in these subgroups compared to the adjustment disorder subgroup. The association was not statistically significant.

Meaning based coping: A majority (60\%) of respondents having an ICD-10 diagnosis of mixed anxiety and depressive disorder and half of those diagnosed with mood (depressive disorder) scored above the cut off score on meaning-based coping, indicating a high use of this coping strategy is these subgroups. A larger number $(70.6 \%)$ of respondents having adjustment disorder scored below the cut off for this strategy, 
indicating low use of this strategy. The association described above was statistically significant (p-value of $0.011)$.

Table 3: Correlation across Diagnoses of Coping Strategies $(n=46)$

\begin{tabular}{|c|c|c|c|c|}
\hline \multicolumn{2}{|c|}{ Coping Strategy } & \multicolumn{3}{|c|}{ ICD-10 Diagnosis } \\
\hline $\begin{array}{l}\text { Active } \\
\text { avoidance } \\
\text { coping }\end{array}$ & $\begin{array}{l}\text { Score } \\
\text { on } 16\end{array}$ & $\begin{array}{l}\text { Adjustment } \\
\text { disorder } \\
(\mathbf{1 0 0 \% )} \\
(\mathrm{n}=17)\end{array}$ & $\begin{array}{l}\text { Mixed } \\
\text { anxiety } \\
\text { and } \\
\text { depressive } \\
\text { disorder } \\
(100 \%) \\
(n=15)\end{array}$ & $\begin{array}{l}\text { Mood (depressive) } \\
\text { disorder(100\%) } \\
(\mathrm{n}=14)\end{array}$ \\
\hline & $>6$ & $8(47.1)$ & $11(73.3)$ & $12(85.7)$ \\
\hline & $\leq 6$ & $9(52.9)$ & $4(26.7)$ & $2(14.3)$ \\
\hline
\end{tabular}

Chi square value $=6.329, \mathrm{p}$ - value $=0.097 ;$ not statistically significant .

\begin{tabular}{|c|c|c|c|c|}
\hline \multirow[t]{3}{*}{$\begin{array}{l}\text { Active } \\
\text { confronting } \\
\text { coping }\end{array}$} & $\begin{array}{l}\text { Score } \\
\text { on } 28\end{array}$ & $\begin{array}{l}\text { Adjustment } \\
\text { disorder } \\
(100 \%) \\
(n=17)\end{array}$ & $\begin{array}{l}\text { Mixed } \\
\text { anxiety } \\
\text { and } \\
\text { depressive } \\
\text { disorder } \\
(100 \%) \\
(n=15)\end{array}$ & $\begin{array}{l}\text { Mood (depressive) } \\
\text { disorder (100\%) } \\
(\mathrm{n}=14)\end{array}$ \\
\hline & $>14$ & $11(64.7)$ & $4(26.7)$ & $8(57.1)$ \\
\hline & $\leq 14$ & $6(35.3)$ & $11(73.3)$ & $6(42.9)$ \\
\hline \multicolumn{5}{|c|}{ Chi square value $=11.539, \mathrm{p}$ - value $=0.009 ;$ statistically significant. } \\
\hline \multirow[t]{3}{*}{$\begin{array}{l}\text { Passive } \\
\text { avoidance } \\
\text { coping }\end{array}$} & $\begin{array}{l}\text { Score } \\
\text { on } 12\end{array}$ & $\begin{array}{l}\text { Adjustment } \\
\text { disorder } \\
(\mathbf{1 0 0 \% )} \\
(\mathrm{n}=17)\end{array}$ & $\begin{array}{l}\text { Mixed } \\
\text { anxiety } \\
\text { and } \\
\text { depressive } \\
\text { disorder } \\
(100 \%) \\
(n=15)\end{array}$ & $\begin{array}{l}\text { Mood (depressive) } \\
\text { disorder } \\
(100 \%)(n=14)\end{array}$ \\
\hline & $>7$ & $9(52.9)$ & $13(86.7)$ & $10(71.4)$ \\
\hline & $\leq 7$ & $8(47.1)$ & $2(13.3)$ & $4(28.6)$ \\
\hline
\end{tabular}

Chi square value $=5.470, \mathrm{p}$ - value $=0.140 ;$ not statistically significant

\begin{tabular}{|l|l|l|l|l|}
\hline $\begin{array}{l}\text { Meaning } \\
\text { Based } \\
\text { Coping }\end{array}$ & Score on 20 & $\begin{array}{l}\text { Adjustment } \\
\text { Disorder } \\
\mathbf{( 1 0 0 \% )} \\
(\mathbf{n = 1 7 )}\end{array}$ & $\begin{array}{l}\text { Mixed } \\
\text { anxiety and } \\
\text { depressive } \\
\text { disorder } \\
\mathbf{( 1 0 0 \% )} \\
(\mathbf{n = 1 5 )}\end{array}$ & $\begin{array}{l}\text { Mood } \\
\text { (depressive } \\
\text { disorder) } \\
\mathbf{( 1 0 0 \% )} \\
(\mathbf{n = 1 4 )}\end{array}$ \\
& & & $9(60)$ & $7(50)$ \\
\cline { 2 - 5 } & $>11$ & $5(29.4)$ & $6(40)$ & $7(50)$ \\
\cline { 2 - 5 } & $\leq 11$ & $12(70.6)$ & 9 & \\
\hline
\end{tabular}

Chi square value $=11.162, \mathrm{p}$ - value $=0.011 ;$ statistically significant

\section{Socio-demographic variables}

Certain socio-demographic variables may serve as risk factors to increase the likelihood of psychological stress and also influence the type of coping strategy used [20]. This study recruited a total of 68 females diagnosed to be having infertility (primary or secondary). Nearly $75 \%$ of the sample was less than 30 years old. Most of the females had a_middle school education (32.4\%), were housewives (63.2\%), stayed in a joint family $(69.1 \%)$ and belonged to the lower middle class $(60.3 \%)$. 
In a study conducted by Patel et al in 2016 [21] of the 300 females recruited, the age range was 20-49 years with a median of 29 years. $43 \%$ of the women were educated up till high-school, A majority of them were house-wives (64\%) belonging to a joint family (55\%), and around half of them belonged to lower-middle or middle socioeconomic status. This is similar to the findings in our study.

In a study by Yazori AL [12] of the 129 participants included (80.6\% of which were females), a majority of the sample (87\%) was less than 30 years old. A larger number (51.3\%) of their sample lived in an extended family, compared to a nuclear family (42.6\%). These findings were similar to the findings of the current study. Their sample showed a majority (63.6\%) had university level of education, $20.2 \%$ finished secondary level; and few (4.7\%) had a higher education (post-graduation/ $\mathrm{PhD}$ ). As opposed to the sample recruited in this study, a majority (63.6\%) of the total respondents were employed; with $34.1 \%$ of the sample being unemployed.

Knowledge on the socio-demographic profile of those with infertility can be of significance as various studies have shown that the level of education and occupational /social class of the infertile subject can have a bearing on the way infertility as a stressor is appraised. This, in turn, can significantly influence the type of coping strategy used to combat the infertility stress [22, 23].

\section{Prevalence, type and severity of psychiatric morbidity}

In addition to facing problems in the body organs, infertile couples experience psychological problems such as depression, anxiety, aggression, guilt, criticism, feeling of discontent, lack of self-esteem, jealousy, interpersonal relationship difficulties, lack of confidence, feeling of being unwanted, lack of flexibility with their partner, and sexual dissatisfaction. Various studies have found that anxiety is significantly higher in infertile couples when compared to the general population, with prevalence estimates varying from as low as $8 \%$ to $28 \%$ or even more [24, 7, 25]. Matsubayashi et al. [26] and Wischman [27] reported that depression is more common among infertile women as compared to fertile or pregnant women and infertile men respectively. In the current study, all the respondents were screened by psychiatric interview and using the HAM-A and MADRS for presence of anxiety and depressive symptoms.

\section{Prevalence of psychiatric morbidity}

Out of the total number of patients recruited, psychiatric morbidity was seen in a majority i.e. 46 out of 68 (67.7\%) of females with infertility. The two recent Indian studies by Pankaj Verma et al and Patel et al had comparable findings when assessing prevalence of psychiatric morbidity in infertile patients $(68.8 \%$ and 79 $\%$ respectively) [20-21]. However, two other studies found comparatively lower rates of prevalence of psychiatric morbidity at $46.4 \%$ and $44 \%$ respectively [28-29].

\section{Type of psychiatric disorder (ICD-10 diagnosis)}

In this study, out of those having psychiatric morbidity, a majority (37\%) had an ICD-10 diagnosis of Adjustment disorder, followed by Mixed anxiety and depressive disorder seen in $32.6 \%$ and Mood (depressive) disorders (30.4\%). Findings similar to the current study were reported by Guerra et al. [8] who found adjustment and anxiety disorders to be the most common diagnoses in their sample.

A few studies have found anxiety disorders to be more in infertile women compared to depression. A research by Abedinia et al. shows that $86.8 \%$ of infertile women had anxiety and $40.8 \%$ had depression [14]. Ramazanzadeh et al. also found more number of infertile women $(68.8 \%)$ suffered from anxiety compared to depression [30]. A study by Upkong MD however reported higher prevalence of depression (43\%) in infertile females compared to anxiety (37.5\%) [28]. Prevalence estimates of depression varied from $62 \%$ in a Ghana study14compared to a study done in Poland [31] where the rates of depression were $35.44 \%$. In our study, the prevalence of depression was $30.4 \%$ in those with an ICD-10 diagnosis of mood (depressive) disorder. However, it must be noted that depressive symptoms were present in all those with psychiatric morbidity (i.e. 67.7\%) when screened by MADRS. 


\section{Severity of anxiety and depressive symptoms Anxiety scores on HAM-A}

Out of those patients with psychiatric morbidity, nearly half (54.4\%) were shown to have anxiety symptoms. Larger number (37\%) had mild anxiety and $17.4 \%$ had moderate anxiety on the HAM-A. The study by Arifuddin et al, showed a majority of their sample to be suffering from moderate anxiety (76 \%) and lesser number (24\%) had mild anxiety [32].

\section{Depression scores on MADRS}

In our sample, all patients having psychiatric morbidity ( $\mathrm{n}=46,100 \%)$ screened positive for depression on MADRS. A majority (73.9\%) were shown to have mild depression whereas $26.1 \%$ had moderate depression on the MADRS. Noorbala et al, (2007) used Beck's questionnaire to study the prevalence of depression and found similar findings with respect to severity of depression- a majority (30\%) suffered from mild depression, followed by moderate depression (12.5\%) and very few (5.3\%) had severe depression [33]. Contrary to this, Arifuddin et al. found that among females, a majority had severe depression, followed by moderate depression, and very few had mild or no depression [32].

\section{Coping strategies used by females with infertility}

To understand the use of each coping strategy, each of the four coping strategy subscales were dichotomized into high/low using the cut offs obtained from the ROC curves plotted. Higher score implied more use of the particular coping strategy. In the sample studied, nearly $60 \%$ of the patients scored above the respective cut offs for each coping strategy indicating a high use of all four coping strategies in the population studied. However, a majority of the respondents with infertility scored above the cut off for the avoidance strategies respectively (passive avoidance: $64.7 \%$ and active avoidance: $63.2 \%$ ). In a study conducted in Iran by Aflakseir and Zarei, the highest score obtained by infertile women was on passive avoidance coping as was the case in this study. However, contrary to this study, they found the lowest score obtained was on activeavoidance [34]. Few other studies also found passive coping style to be positively associated with health complaints, depression, anxiety and complicated grief in females with chronic illnesses such as infertility $[34-35,22]$.

\section{Correlation between psychiatric morbidity and coping strategies used}

Studies have shown that infertile females with significant coping difficulties experience 5 times greater infertility stress and healthy coping abilities are one of the major psychological factors that can buffer them from infertility stress [36-37]. The use of active avoidance coping involves avoiding pregnant women or children, walking away when pregnancy is discussed, keeping feelings to oneself etc. On the other hand, passive avoidance coping includes hoping for a miracle to happen, believing all that can be done is to wait, and having fantasies and wishes. In the sample studied, a majority (67.4\%) of those with psychiatric morbidity had a high use of active and passive avoidance coping (69.6\%). This association was not found to be statistically significant. Schmidt et al. in their study have reported that among both men and women high use of active-avoidance coping predicted high fertility problem stress. Another study by Lykeridou showed a positive correlation between active-avoidance coping and both state and trait anxiety [22]. The high use of active-avoidance coping can be interpreted as a kind of defence strategy protecting the infertile participant from some of the emotional burdens of the infertility experience [38]. This can also explain the findings in the current study sample, where those with depressive and anxiety symptoms showed high use of active avoidance coping. However, Verhaak et al found no relationship between problem-focused, active coping and changes in anxiety or depression, and failed to support the predictive value of avoidance coping [39].

The use of active confronting coping involves showing feelings, asking others for advice, reading or watching programmes related to infertility, talking about treatment related stress etc. Meaning based coping, involves adding meaning to the problem of infertility, viewing it in a positive light and perceiving the challenges of infertility as a means to grow individually and as a couple.

In our sample, a majority (81.8\%) of those who did not have psychopathology had a high use of both active confronting and meaning based coping respectively. Both these associations were found to be statistically significant. This implies that higher use of active confronting and meaning based coping are associated with 
significantly lesser chances of developing psychiatric morbidity and can have a protective role against development of psychopathology. The findings of the Iranian study by Aflakseir et al reflected findings similar to the current study in that they found meaning-based coping strategy was the strongest predictor of low infertility stress [34].

\section{Correlation across diagnoses of coping strategy used}

Though many studies have studied fertility problem stress and compared it with coping strategies used, fewer studies have correlated and compared the psychiatric diagnoses with the coping strategies used. The findings of the current study with respect to the same have been discussed below. In those with Adjustment disorder, majority (64.7\%) used active confronting as a coping strategy. Majority (86.7\%) of those with Mixed anxiety and depressive disorder, used passive avoidance as a coping strategy. The coping strategy used most by those with Mood (depressive) disorder, was active avoidance (85.7\%). The high use of active confronting coping in those with Adjustment disorder was found to be statistically significant, implying that those with Adjustment disorder are more likely to use active confronting coping.

This was in keeping with the findings of Benyamini et al. (2009) who reported that problem management and active confronting strategies were associated with higher levels of infertility distress and worse adjustment [40]. Contrary findings were found by Lechner et al (2006) [41] who reported that use of active coping style was not associated with depression, anxiety and complicated grief. The use of meaning-based coping by $60 \%$ of those with Mixed anxiety depression, and by half of those with Mood (depressive) disorder was also found to be statistically significant, implying that more than half of those with Mixed anxiety and depressive disorder and at least half of those with Mood (depressive) disorder are likely to use meaningbased coping. In our study, a high use of meaning-based coping was seen in both groups of infertile women, those with psychiatric morbidity and those with no psychiatric morbidity, and both these findings were found to be statistically significant.

The use of meaning-based coping even in those females with psychiatric morbidity can be due to the fact that adding meaning to a stressor like infertility which has psychosocial ramifications may be crucial for these women to keep daily positive affect as it would suppress the negative pain effect that infertility could have on their emotional state. A study by Kraaij, Garnefski, and Vlietstra found use of positive reappraisal, in addition to rumination, self-blame and catastrophization to be related with presence of depressive symptoms [42]. Litt et al, on the other hand, found no association between infertility distress and seeking meaning among women [43]. Most other studies show that problem appraisal strategies and use of meaning based coping were a predictor for better adjustment and low fertility problem stress [44, 37, 40].

\section{CONCLUSION}

\section{Prevalence of psychiatric morbidity in females with infertility}

Out of the 68 patients recruited, psychiatric morbidity was seen in a majority i.e. $67.7 \%$ of females with infertility. Out of those having psychiatric morbidity, a majority (37\%) had an ICD-10 diagnosis of Adjustment disorder, followed by Mixed anxiety and depressive disorder (32.6\%) and Mood (depressive) disorders (30.4\%). Of those having an Adjustment disorder, an equal number i.e. $35.2 \%$ had a diagnosis of Adjustment disorder with mixed anxiety and depressive reaction and Adjustment disorder with brief depressive reaction respectively. A prolonged depressive reaction was seen in $29.4 \%$ of females having Adjustment disorder. Of those with Anxiety disorder, all the females had a Mixed anxiety and depressive disorder. From those having a Mood (depressive) disorder, a larger number (42.9\%) had a mild depressive episode. Dysthymia with moderate or mild depressive episode was diagnosed in $28.6 \%$ and $7.1 \%$ respectively. $21.4 \%$ were diagnosed with Moderate depressive episode.

\section{Coping strategies used by females with infertility}

Nearly $60 \%$ of the patients scored above the respective cut offs for each coping strategy indicating a high use of all four coping strategies in the population studied. The passive avoidance coping was used most $(64.7 \%)$ followed by active avoidance (63.2\%), active confronting (60.3\%), and meaning based coping (57.4\%). 


\section{Correlation of psychiatric morbidity with coping strategies used}

Correlation between psychiatric morbidity and coping strategies used, showed a majority of those with psychiatric morbidity had a high use of active avoidance (67.4\%) and passive avoidance coping (69.6\%). This association however, was not found to be statistically significant. Majority $(81.8 \%)$ of those who did not have psychiatric morbidity had a high use of active confronting and meaning based coping respectively. Both these associations were found to be statistically significant. This implies that higher use of active confronting and meaning based coping is associated with significantly lesser chances of developing psychiatric morbidity and use of these can have a protective role against development of psychopathology.

\section{Correlation across diagnoses of coping strategies used}

A correlation across diagnosis with coping strategies used found that of those with Adjustment disorder, majority (64.7\%) used active confronting as a coping strategy. This association was statistically significant. Of those with Mixed anxiety and depressive disorder, majority (86.7 \%) used passive avoidance coping and of those with Mood (depressive) disorder, majority ( $85.7 \%$ ) used active avoidance as a coping strategy.

\section{RECOMMENDATIONS}

- There is a need to assess all females with infertility for the presence of anxiety or depressive symptoms.

- The gynaecologists must be made aware that infertile females frequently have associated psychiatric morbidity. Accordingly, an empathetic approach when handling these patients and referral to a psychiatrist when required should be encouraged.

- Understanding the coping styles used by females with infertility, can help design appropriate psychological interventions specific to that patient. This can enable patients handle the infertility related distress in healthier ways.

\section{REFERENCES}

1. Rowe PJ, Comhaire F, Hargreave T, Mellows H. WHO manual for the standardized investigation and diagnosis of the infertile couple. Press Syndicate of the University of Cambridge, Cambridge, 1993.

2. Joshi HL, Singh R, Bindu M. Psychological distress, coping and subjective wellbeing among infertile women. J Indian Acad Appl Psychol 2009;35(2):329-6.

3. Sadock BJ. Kaplan \& Sadock's comprehensive textbook of psychiatry. Philadelphia, PA: lippincott Williams \& Wilkins; 2000 Feb.

4. Stotland NL. Contemporary issues in obstetrics and gynecology for the consultation-liaison psychiatrist. Psychiatr Serv 1985;36(10):1102-8.

5. Dyer S, Lombard C, Van der Spuy Z. Psychological distress among men suffering from couple infertility in South Africa: a quantitative assessment. Hum Reprod 2009;24(11):2821-6.

6. Dyer SJ. The value of children in African countries-insights from studies on infertility. J Psychosom Obstet Gynecol 2007;28(2):69-77.

7. Chen TH, Chang SP, Tsai CF, Juang KD. Prevalence of depressive and anxiety disorders in an assisted reproductive technique clinic. Hum Reprod 2004;19(10):2313-18.

8. Guerra D, Llobera A, Veiga A, Barri PN. Psychiatric morbidity in couples attending a fertility service. Hum. Reprod 1998;13(6):1733-6.

9. Demyttenaere K, Nijs P, Evers-Kiebooms G, Koninckx PR. The effect of a specific emotional stressor on prolactin, cortisol, and testosterone concentrations in women varies with their trait anxiety. Fertil Steril 1989;52(6):942-8.

10. Merari D, Feldberg D, Elizur A, Goldman J, Modan B. Psychological and hormonal changes in the course of in vitro fertilization. J Assist Reprod Genet 1992;9(2):161-9.

11. Lazarus RS, Folkman S. Stress, appraisal, and coping. Springer publishing company; 1984.

12. AL-Yazori TA. Relationship between infertility related Stress and Type of Coping among Infertile Males and females-Gaza Strip. [Thesis] Degree of Master in Community Mental Health. Islamic University Gaza. 20112012. 
13. Schmidt L, Holstein BE, Christensen U and Boivin J. Communication and coping as predictors of fertility problem stress: cohort study of 816 participants who did not achieve a delivery after 12 months of fertility treatment. Hum Reprod 2005;20(11):3248-56.

14. Alhassan A, Abaidoo CS: Effect of maternal age on endometrial morphology among Ghanaian infertile women. J Med Biomed Sci 2012;1(1):9-13.

15. Oberoi SS. Updating income ranges for Kuppuswamy's socio-economic status scale for the year 2014. Indian J Pub Health 2015;59(2):156-60.

16. World Health Organization. The ICD-10 classification of mental and behavioural disorders: clinical descriptions and diagnostic guidelines. Geneva: World Health Organization; 1992.

17. Montgomery SA, Asberg MA. A new depression scale designed to be sensitive to change. Br J Psychiaty 1979;134(4):382-9.

18. Hamilton MA. The assessment of anxiety states by rating. Br J Med Psychol 1959;32(1):50-5.

19. Swets JA. Indices of discrimination or diagnostic accuracy: their ROCs and implied models. Psychol Bull 1986 ;99(1):100-8.

20. Verma P, Rastogi R, Sachdeva S, Gandhi R, Kapoor R, Sachdeva S. Psychiatric morbidity in infertility patients in a tertiary care setup. J Clin Diagn Res 2015;9(9):VC01.

21. Patel A, Sharma PS, Narayan P, Binu VS, Dinesh N, Pai PJ. Prevalence and predictors of infertility-specific stress in women diagnosed with primary infertility: A clinic-based study. J Hum Reprod Sci 2016;9(1):28 -34.

22. Lykeridou K, Gourounti K, Sarantaki A, Loutradis D, Vaslamatzis G, Deltsidou A. Occupational social class, coping responses and infertility- related stress of women undergoing infertility treatment. J Clin Nurs 2011;20(13- 14):1971-80.

23. Schmidt L, Christensen U, Holstein BE. The social epidemiology of coping with infertility. Hum Reprod 2005;20(4):1044-52.

24. Anderson KM, Sharpe M, Rattray A, Irvine DS. Distress and concerns in couples referred to a specialist infertility clinic. J Psychosom Res 2003;54(4):353-5.

25. Womens mental health [Internet].[place unknown]:Fertility and Mental Health;[publisher unknown];[date unknown]. Available from:https://womensmentalhealth.org/specialty-clinics/infertility-and-mental-health/

26. Matsubayashi H, Hosaka T, Izumi SI, Suzuki T, Makino T. Emotional distress of infertile women in Japan. Hum Reprod 2001;16(5):966-9.

27. Wischmann T. [Psychosocial aspects of fertility disorders]. Der Urologe Ausg A 2005;44(2):185-94.

28. Upkong D, Orji EO. Mental health of infertile women in Nigeria. Turk Psikiyatri Dergisi 2006;17(4):259.

29. Ramezanzadeh F, Aghssa MM, Abedinia N, Zayeri F, Khanafshar N, Shariat M, Jafarabadi M. A survey of relationship between anxiety, depression and duration of infertility. BMC Wom Health 2004;4(1):1.

30. Abedinia N, Ramazanzadeh F, Aghsa MM. Relationship between anxiety and depression with duration of pregnancy. Quartenary Journal Payesh 2003;4:153-8.

31. Ganguly S, Unisa S. Trends of infertility and childlessness in India: findings from NFHS data. Obstetr Gynaecol 2010;2(2):131-8.

32. Arifuddin A, Nusrath F, Sandeep KV, Aleem AK, Ramakrishna P, D Souza R, Rozatti R. Psychological evaluation of couples attending the infertility clinic in atertiary care, teaching hospital. Int J Curr Res Acad Rev 2014;2(2):133-47.

33. Noorbala AA, Ramezanzadeh F, Abedinia N, Yazdi SA, Jafarabadi M. Study of psychiatric disorders among fertile and infertile women and some predisposing factors. J Fam Reprod Health 2007;1(1):6-11.

34. Aflakseir A, Zarei M. Association between coping strategies and infertility stress among a group of women with fertility problem in Shiraz, Iran. J Reprod Infertil 2013;14(4):202-6.

35. Matsubayashi H, Hosaka T, Izumi SI, Suzuki T, Kondo A, Makino T. Increased depression and anxiety in infertile Japanese women resulting from lack of husband's support and feelings of stress. Gen Hosp Psychiatry 2004;26(5):398-404.

36. Stanton AL, Tennen H, Affleck G, Mendola R. Coping and adjustment to infertility. J Soc Clinic Psychol 1992;11(1):1.

37. Terry DJ, Hynes GJ. Adjustment to a low-control situation: Reexamining the role of coping responses. J Pers Soc Psychiatry 1998;74(4):1078-85.

38. Schmidt L. Infertility and assisted reproduction in Denmark. Dan Med Bull 2006;53(4):390-417.

39. Verhaak CM, Smeenk JM, Van Minnen A, Kremer JA, Kraaimaat FW. A longitudinal, prospective study on emotional adjustment before, during and after consecutive fertility treatment cycles. Hum Reprod 2005;20(8):2253-60.

40. Gourounti K, Anagnostopoulos F, Vaslamatzis G. Psychosocial predictors of infertility related stress: a review. Curr Wom Health Rev 2010;6(4):318-31. 
41. Lechner L, Bolman C, Van Dalen A. Definite involuntary childlessness: associations between coping, social support and psychological distress. Hum Reprod 2007;22(1):288-94.

42. Kraaij V, Garnefski N, Vlietstra A. Cognitive coping and depressive symptoms in definitive infertility: a prospective study. J Psychosom Obst Gynecol 2008;29(1):9-16.

43. Litt MD, Tennen H, Affleck G, Klock S. Coping and Cognitive factors in adaptation toin vitro fertilization failure. J Behav Med 1992:15(2):171-87.

$* * * * * * * * * * * * * * * * * * * * * * * * * * * * * * * * * * * *$

$$
\begin{gathered}
\text { Acknowledgements - Nil } \\
\text { Conflict of Interest - Nil; } \\
\text { Funding - Nil }
\end{gathered}
$$

